Article

\title{
Exergy and Exergoeconomic Analyses of Air Conditioning Applications Integrated with an Air Membrane Exchanger
}

\author{
Abdulrahman S. Almutairi ${ }^{1, *}$, Abdulrahman H. Alenezi ${ }^{1}{ }^{1}$, Hamad M. AlHajeri ${ }^{1}$, Saad F. Alazemi ${ }^{1}$, \\ Hamad H. AlMutairi ${ }^{1}$ and Bashar Alzuwayer ${ }^{2}$ \\ 1 Department of Mechanical Power and Refrigeration Technology, College of Technological Studies, P.A.A.E.T., \\ Kuwait City 70654, Kuwait; ah.alenezi@paaet.edu.kw (A.H.A.); hm.alhajeri@paaet.edu.kw (H.M.A.); \\ sf.almokmesh@paaet.edu.kw (S.F.A.); hhh.almutairi@paaet.edu.kw (H.H.A.) \\ 2 Department of Automotive Mechanics and Marine Engineering Technology, College of Technological Studies, \\ P.A.A.E.T., Kuwait City 70654, Kuwait; bb.alzuwayer@paaet.edu.kw \\ * Correspondence: asa.almutairi@paaet.edu.kw
}

check for

updates

Citation: Almutairi, A.S.; Alenezi,

A.H.; AlHajeri, H.M.; Alazemi, S.F.; AlMutairi, H.H.; Alzuwayer, B.

Exergy and Exergoeconomic

Analyses of Air Conditioning

Applications Integrated with an Air

Membrane Exchanger. Processes 2022,

10, 474. https://doi.org/10.3390/

pr10030474

Academic Editor: Ambra Giovannelli

Received: 1 January 2022

Accepted: 22 February 2022

Published: 26 February 2022

Publisher's Note: MDPI stays neutral with regard to jurisdictional claims in published maps and institutional affiliations.

Copyright: (c) 2022 by the authors. Licensee MDPI, Basel, Switzerland. This article is an open access article distributed under the terms and conditions of the Creative Commons Attribution (CC BY) license (https:// creativecommons.org/licenses/by/ $4.0 /)$.

\begin{abstract}
The results obtained from the exergoeconomic and exergy analysis of a model of a generic air conditioning $(\mathrm{A} / \mathrm{C})$ system without and with an air membrane exchanger using three commercially available refrigerants: R410A, R407C, and R134a, are reported. The model used specialized software that was validated against recently published data and showed good agreement. A/C systems are energy intensive and consume a significant portion of global electricity. Improving their efficiency by even a small amount will produce considerable savings, reduce running costs, and lower pollution emissions. The efficiency of the same A/c system without and with a membrane was investigated for different ambient temperatures, relative humidities (RHs), and pressure ratios of the compressor. It was shown that the inclusion of a membrane improved the efficiency of the system for all three refrigerants tested, particularly at higher ambient temperature. Both the coefficient of performance and exergetic efficiency reduced with the increase in the pressure ratio due to increasing fuel exergy and losses. In all system components except one, it was found that the source of the cost is inefficiencies; hence, increasing the efficiency at the expense of the non-exergy cost will improve the cost effectiveness of the entire system.
\end{abstract}

Keywords: exergoeconomic; membrane; air conditioning; refrigerants; thermophysical

\section{Introduction}

Air conditioning $(\mathrm{A} / \mathrm{C})$ systems are widely used all over the world and contribute significantly to the ever-growing demand for electricity. The provision of a suitable indoor environment is the primary goal of A/C systems, which can be achieved using many different devices, simpler ones based on heat transfer alone and more complex systems combining heat and mass transfer. Heat transfer devices use several forms of heat exchangers including condensers, evaporators, and sensible heat recovery exchangers. Cooling towers, humidifiers, dehumidifiers, and regenerators are representatives of heat and mass transfer devices.

In warm climates, a comfortable working and living environment can be achieved by cleaning, cooling, and dehumidifying outdoor air and circulating it internally. The technologies widely used to remove the moisture in the air are desiccators or direct cooling using chillers. Both techniques are energy intensive, and the use of desiccants to remove moisture from the air may be simple, but carries the risk of cross-contamination [1-4].

In the state of Kuwait, residential, industrial, and commercial buildings constitute about $70 \%$ of total energy consumption and are classified as high-energy-demand systems. Enhancing the performance of these systems even in a small way would save an enormous amount of energy and significantly mitigate their environmental impact. 
A promising technique currently being developed is the use of membranes for dehumidification. The technology relies on the physical fact that water vapor molecules are more condensable than the gases typically found in air, because of their smaller kinetic diameter of $265 \mathrm{pm}$ compared to $346 \mathrm{pm}$ for oxygen molecules and $364 \mathrm{pm}$ for nitrogen molecules [5] These differences in properties can be used in conjunction with a suitable membrane to dehumidify air. The water molecules permeate through the membrane; other gases found in the air do so as well, but to a much lesser extent. As there is no phase change in the dehumidification process nor any contact between incoming fresh air and outgoing stale air streams, the process has minimal energy consumption and simultaneously eliminates the cross-contamination problems [6].

Dehumidification in $\mathrm{A} / \mathrm{C}$ systems has been the subject of a substantial amount of work extending back well over half a century, with commercially available central A/C units for commercial premises widely used in the 1970s [7]. More recently, investigators have studied how the arrangements of membranes can be used to act both as dehumidifiers and heat exchangers; for example, Huang et al. [8] investigated how changing the geometry (height of the channels) of a three-dimensional array of five plate membranes of the same hexagonal shape stacked one on top of another affected the transfer of heat and water. Increasing the channel height for a constant channel width and flow velocities had a significant positive effect on its efficiency for both heat and water transfer.

Nizovtsev et al. [9] investigated the performance of air-air heat exchangers subject to periodic changes in the airflow direction, both analytically and experimentally. It was demonstrated that decreasing the flow rate increased the effectiveness, showing a linear relation between the two parameters. It was also found that changing the relative periodicity of the two flow rates could be used to control the air temperature leaving the exchanger.

El-Dessouky et al. [10] introduced a novel A/C system that combined membrane and evaporative cooling using operating conditions that reflected Kuwait's summer, with inlet temperatures that varied between $35^{\circ} \mathrm{C}$ and $50{ }^{\circ} \mathrm{C}$ and relative humidity $(\mathrm{RH})$ values of between $20 \%$ and $60 \%$. The proposed system showed considerable energy savings compared to conventional mechanical vapor compression systems and much higher sensitivity to the condition of the incoming air. Lingo and Roy [11] carried out an exergetic study of residential HVACs by evaluating the cooling demand in a building. They reported that using heat exchangers to precondition the air streams could reduce the cooling demand.

Zaw et al. [12] analyzed the use of membrane- based air dehumidification units operating in a tropical climate with the membrane dehumidification driven by the vapor pressure gradient between streams. These authors concluded that membrane dehumidification is a suitable technique for use as a precursor to more complex $\mathrm{A} / \mathrm{C}$ systems and as a stand-alone unit. Xing et al. [13] introduced a novel zeolite membrane in the form of a thin flat sheet for air dehumidification. The membrane was tested over several ranges of separation and climate conditions. The results indicated that using membrane dehumidifiers enhanced the energy efficiency of an A/C system for separation factors greater than 200. Zhang and Niu [14] conducted a thermodynamic analysis of air membranes for conditioned ventilation in Hong Kong. The results showed that annual energy savings of as much as $58 \%$ were possible when a membrane was used to condition the air during the ventilation process. Zhang et al. [15] added a membrane-based heat exchanger to a dehumidification system, evaluated its performance using R134a as a refrigerant, and reported an annual energy savings of about 33\%. Zhang [16] published a comparative study of air dehumidification systems comparing a membrane-based total heat exchanger with three alternatives: mechanical dehumidification with a heat pump, mechanical dehumidification with a sensible heat exchanger, and a heat pump incorporating an active desiccant wheel and evaporative cooler. The results showed the membrane total heat recovery consumed the least primary energy.

Liang et al. [17] investigated experimentally and numerically the performance of a membrane air dehumidification system under different operating conditions. The intro- 
duction of the membrane improved the efficiency of the dehumidification system to a much greater extent than changes in external weather conditions. Al-Sulaiman [18] carried out energetic and exergetic analyses for an A/C system with and without an air membrane heat and mass exchanger. This study confirmed that including a membrane in an A/C system significantly improved the performance. Al-Sulaiman [19] also carried out a thermodynamic analysis of the same $\mathrm{A} / \mathrm{C}$ system with an air membrane using different refrigerants. The outcomes obtained confirmed that using a membrane exchanger enhanced the efficiency of the A/C system.

Numerous researchers are now using an exergy approach to investigate the performance of HVAC systems to obtain useful information concerning the sources of the system inefficiencies. Voloshchuk et al. [20] conducted an exergy analysis of a refrigeration system using a new advanced approach to evaluate avoidable endogenous/exogenous parts of the exergy destruction. The proposed method showed quite different results compared to conventional advanced exergy analysis, in particular for the values associated with the compressor and the condenser.

Gullo et al. [21] used an exergy approach to analyze the performance of transcritical carbon dioxide R744 refrigerant in the refrigeration systems of selected supermarkets. The systems included: parallel compression, parallel compression with overfed evaporators, and parallel compression with overfed evaporators and two-phase ejectors. The total irreversibilities' reduction for the ejector arrangement was about $9.3 \%$ with $13.5 \%$ of avoidable destruction.

Đuranović et al. [22] used an exergy approach to analyze the winter performance of an air conditioning system. It was reported that the heat transferred across the heat exchanger contributed much more to total exergy destruction than did the humidification and mixing process.

Yildiz et al. [23] used sustainability and exergy analyses to experimentally examine the performance of an evaporative cooling system under four distinct operating conditions. They reported a decrease in exergy efficiency under positive pressure, but an increase under negative pressure at high air speed.

Blanco-Marigorta et al. [24] used an exergetic approach to analyze two indirect evaporative coolers of different constructions. They found that doubling the area of the heat exchanger increased the exergy destruction. For both constructions, it was found that the higher the inlet dry bulb temperature for the primary air, the greater the exergy losses and exergy destruction.

Although numerous studies are available in the literature relating to air membranes, no studies in the literature address an integrated system based on an exergoeconomic analysis. Furthermore, no reports were found in the literature of investigations of the effect of changing industrial refrigerants on system performance; yet, it is well known that the chemical and thermodynamic properties of the working fluids of $\mathrm{A} / \mathrm{C}$ and refrigerant systems have a substantial impact on performance. To simulate the system performance more accurately, the actual thermo-physical properties of the refrigerants were used in the modelling processes.

The contributions of the planned investigation were:

1. The use of exergy and energy analyses to make an assessment of the effect on system performance of adding membranes to $\mathrm{A} / \mathrm{C}$ systems;

2. An investigation of the effect on system performance of changing the working fluid in the A/C system;

3. An exergoeconomic analysis of the proposed system to assess its cost effectiveness.

\section{System Description}

This study investigated an $\mathrm{A} / \mathrm{C}$ system with an integral air membrane heat and mass exchanger; see Figure 1. The fresh air (A) enters the air membrane to exchange heat and humidity with the exhaust air (E). The stream of fresh air at (B) has a reduced temperature and moisture content. The cooled and dehumidified fresh air enters the evaporator at (B) 
and transfers heat to the refrigerant, further reducing its temperature. After that, the cold fresh air moves to the second or booster condenser at $(C)$, then into the occupied space at (D). The booster condenser is used to provide more precise control of the air temperature entering the occupied space.

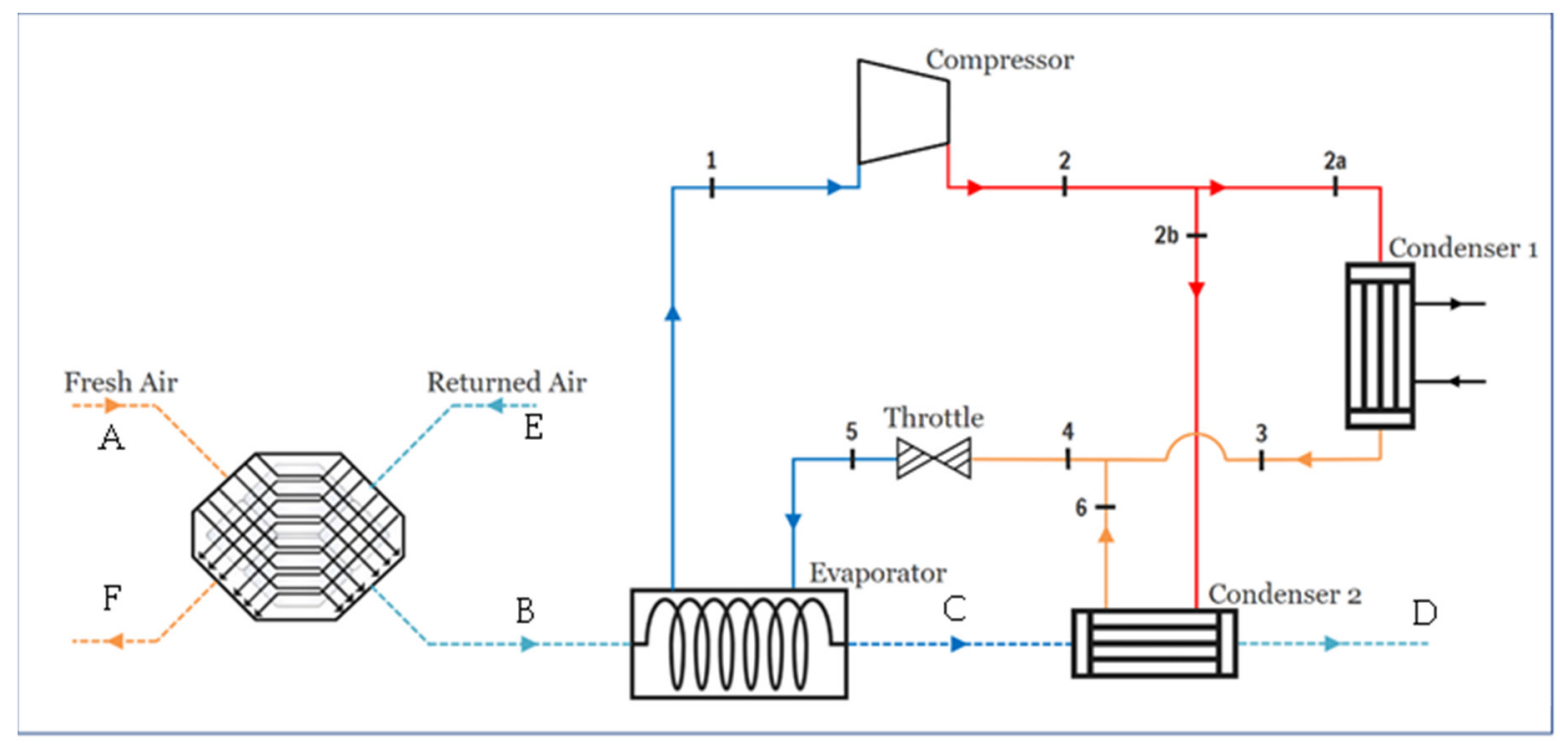

Figure 1. Schematic diagram of an air membrane integrated into an air conditioning system.

The refrigerant enters the compressor at Point (1) as a saturated vapor and exits as a superheated vapor with a temperature higher than the surrounding medium. The highpressure, high-temperature refrigerant is driven by the compressor to Condenser 1 and the booster condenser, which are effectively arranged in parallel. In Condenser 1, the refrigerant ejects heat to the surroundings and exits as a saturated liquid, which mixes with the discharge from the booster condenser at Point (6). Next, the refrigerant enters the throttle as a saturated liquid, and its temperature is reduced by the throttling process to below that of the occupied space. Upon leaving the throttle, Point (5), the refrigerant moves to the evaporator as a low-quality saturated mixture. The flow rates of the refrigerant and inlet air to the evaporator are such that, upon absorbing heat from the fresh air steam, the refrigerant completely evaporates. Finally, the refrigerant is returned to the compressor to complete the cycle.

\section{Methodology}

Traditional energy analysis and evaluation of working systems has, until recently, been carried out using the first law of thermodynamics. Unfortunately, such an analysis is incapable of providing information on either how high-temperature thermal energy degrades during the process or on the relative quality of the different forms of energy. The second law of thermodynamics can be used to overcome this limitation because the second law differentiates between quality and quantity and demonstrates that in any real process, there will be a decrease in the quality of energy.

This has resulted in defining the energy available for useful work as exergy and its quantification as exergy analysis. Exergy and economics are both required to evaluate the cost effectiveness of a thermal process, and this "exergoeconomic" analysis can provide valuable information that cannot be obtained from traditional methods.

In the proposed study, exergoeconomic and exergetic analyses were carried out on the A/C system for a range of operating conditions for three different refrigerants, R407C, R410A, and R134a. The proposed system operates under the steady-state condition, and the heat and pressure losses through the pipes are negligible, with all processes being adiabatic and with heat loss to the atmosphere. The temperature of the surroundings is TA $=35^{\circ} \mathrm{C}$, 
and $\mathrm{RH}=62 \%$. The low pressure in the $\mathrm{A} / \mathrm{C}$ system is $300 \mathrm{kPa}$, and the pressure ratio of the compressor is about 3.5 with $75 \%$ isentropic efficiency. The refrigerant mass flow rate is $0.2 \mathrm{kgs}^{-1}$, and the room temperature, TD, was adjusted to be $20^{\circ} \mathrm{C}$. The membrane latent effectiveness $\varepsilon_{L}=0.9$, and the sensible effectiveness $\varepsilon_{S}=0.8$.

The mathematical model was developed based the first and second laws of thermodynamics. Exergy analysis is one of the most popular approaches based on the second law of thermodynamics. The general exergy balance for steady-flow systems can be written as [2]:

$$
\sum\left(1-\frac{T_{o}}{T_{k}}\right) \dot{Q}_{k}-\dot{W}+\sum_{i} \dot{m}_{i} e x_{i}-\sum_{e} \dot{m}_{e} e x_{e}-\dot{E}_{d}=0
$$

where $T$ is the temperature in Kelvin and the subscript $k$ stands for the value of the component as is, while the subscript $o$ is the value of the property in its reference state. $\dot{Q}$ and $\dot{W}$ are the heat and work interactions between the system and its surrounding. The mass flow rate and exergy per unit mass flow rate are given by $\dot{m}$ and $e x$, respectively. The subscripts $i$ and $e$ represent the property state of the inlet and exit streams, respectively. The total exergy consists of four components: physical, potential, kinetic, and chemical, and for a given stream is defined as:

$$
\dot{E}_{x}=\dot{E}_{p h}+\dot{E}_{c h}+\dot{E}_{p e}+\dot{E}_{k e}
$$

The potential and kinetic exergies are negligible due to their insignificant contributions, while chemical exergy is omitted for all components except in the membrane because there is no change in the molecular structure and concentration of the refrigerant. The remaining term is physical exergy, consists of mechanical and thermal exergy, and is given by the expression $[25,26]$ :

$$
\dot{E}_{p h}=\dot{m}\left[\left(h-h_{o}\right)-T_{o}\left(s-s_{o}\right)\right]
$$

The proposed system inefficiencies can be calculated from exergy destruction, as illustrated in Table 1, for the given components.

\begin{tabular}{|c|c|c|c|}
\hline No. & Component & Exergy Destruction Rate & Exergetic Efficiency \\
\hline 1 & Compressor & $\dot{E}_{d, c o m p}=\dot{E}_{x 1}-\dot{E}_{x 2}+\dot{W}=\dot{m} T_{o}\left(s_{1}-s_{2}\right)$ & $\eta_{e x}=1-\frac{\dot{E}_{d, c o m p}}{\dot{W}}$ \\
\hline 2 & Condenser 1 & $\begin{array}{c}\dot{E}_{d, \text { cond } 1}=\dot{E}_{x 2 a}-\dot{E}_{x 3} \\
=(1-\mathrm{y}) \dot{m}\left[T_{o}\left(s_{2 a}-s_{3}\right)+\frac{\dot{Q}_{H 1}}{T_{H 1}}\right]\end{array}$ & $\eta_{e x}=1-\frac{\dot{E}_{d, c o n d 1}}{\dot{E}_{x 2 a}-\dot{E}_{x 3}}$ \\
\hline 3 & $\begin{array}{c}\text { Booster } \\
\text { Condenser } 2\end{array}$ & $\begin{array}{c}\dot{E}_{d, \text { cond } 2}=\dot{E}_{x 2 b}-\dot{E}_{x 6} \\
=\mathrm{y} \dot{m}\left[T_{o}\left(s_{2 b}-s_{6}\right)+\frac{\dot{Q}_{H 2}}{T_{H 2}}\right]\end{array}$ & $\eta_{e x}=1-\frac{\dot{E}_{d, c o n d 2}}{\dot{E}_{x 2 b}-\dot{E}_{x 6}}$ \\
\hline 4 & Evaporator & $\begin{aligned} & \dot{E}_{d, \text { evap }}=\dot{E}_{x 1}-\dot{E}_{x 5} \\
= & \dot{m}\left[T_{o}\left(s_{1}-s_{5}\right)-\frac{\dot{Q}_{L}}{T_{L}}\right]\end{aligned}$ & $\eta_{e x}=1-\frac{\dot{E}_{d, \text { evap }}}{\dot{E}_{x 5}-\dot{E}_{x 1}}$ \\
\hline 5 & Membrane & $\dot{E}_{d, \mathrm{~m}}=\dot{E}_{x \mathrm{e}}-\dot{E}_{x \mathrm{f}}+\dot{E}_{x \mathrm{~b}}-\dot{E}_{x \mathrm{a}}$ & $\eta_{e x}=1-\frac{\dot{E}_{d, \mathrm{~m}}}{\dot{E}_{x \mathrm{e}}-\dot{E}_{x \mathrm{f}}}$ \\
\hline
\end{tabular}

Table 1. Exergy destruction rate and exergetic efficiency for the different system components under steady-state conditions. 
The coefficient of performance (COP) concept was used to express the efficiency of the vapor compression refrigeration cycle. The COP is the ratio of heat removed from the occupied space to the required energy input and can be expressed as:

$$
\mathrm{COP}=\frac{\dot{Q}_{\text {evap }}}{\dot{W}_{\text {Comp }}}
$$

The model of the air membrane can be developed numerically using several methods as reported in [17]. In the current study, the energy modelling of the air membrane effectiveness was based on [27], which showed good agreement between its predicted results and experimental results reported in the literature. Furthermore, it is considered simple with respect to finite difference models. The sensible effectiveness and latent effectiveness of the air membrane are defined as follows:

$$
\begin{gathered}
\varepsilon_{S}=\frac{\left(\dot{m}_{A} C p_{(A, B)}\right)\left(T_{A}-T_{B}\right)}{\left(\dot{m} C p_{(A, E) \min }\right)\left(T_{A}-T_{E}\right)} \\
\varepsilon_{L}=\frac{\left(\dot{m}_{A} C p_{(A, B)}\right)\left(\omega_{A}-\omega_{B}\right)}{\left(\dot{m} C p_{(A, E) \text { min }}\right)\left(\omega_{A}-\omega_{E}\right)}
\end{gathered}
$$

where $C p$ is the specific heat of air and $\omega$ refers to the specific humidity.

Evaluating exergy in the air membrane should include both physical and chemical components to achieve equilibrium mechanically and chemically between the reference and dead states. Wepfer et al. [28] established an effective formula to evaluate the exergy of a humid air stream. This equation is a function of air temperature, pressure, and specific humidity, as follows [29]:

$$
\begin{aligned}
\operatorname{ex}_{m a}=T_{o}\left(C_{p a}+\omega C_{p v}\right)\left[T_{r}-1-\ln \left(T_{r}\right)\right] & +R_{a} T_{o}(1+w \omega) \ln \left(P_{r}\right)+R_{a} T_{o}(1+w \omega) \ln \left(\frac{1+w \omega_{o}}{1+w \omega}\right) \\
& +R_{a} T_{o}(w \omega) \ln \left(\frac{\omega}{\omega_{o}}\right)
\end{aligned}
$$

where the subscripts $a$ and $v$ refer to dry air and water vapor; $P_{r}$ and $T_{r}$ are the relative pressure and temperature, respectively. $R$ is the gas constant, and $w$ is a constant of value equal to 1.6081. In the literature, exergy indicators have been introduced to illustrate the waste exergy in overall performance, as well as each individual component. The fuel depletion represents the ratio of the exergy destruction rate to the energy input to the compressor and can be expressed as:

$$
\delta_{x}=\frac{\dot{E}_{d x}}{\dot{W}}
$$

The productivity lack indicator relates the exergy destruction rate to the useful cooling energy produced in the evaporator and can be written as:

$$
\xi=\frac{\dot{E}_{d x}}{\dot{Q}_{\text {evap }}}
$$

The irreversibility ratio, which represents the rate of exergy destruction of each component, $\dot{E}_{d, k}$, divided by the total rate of exergy destruction in the entire system, $\dot{E}_{d, t}$, can be written as:

$$
\gamma_{k}=\frac{\dot{E}_{d, k}}{\dot{E}_{d, t}}
$$


This can show the contribution of each component to the rate of total exergy destruction for the system.

The specific exergy costing method (SPECO) was used to evaluate the cost effectiveness of the proposed system because it is the most popular method reported in the literature [30]. The SPECO method depends on three sequential steps: an initial exergy analysis to identify all exergy streams in the proposed system; then the fuels and products for each component are defined; then the cost is determined from an economic analysis, which includes fuel, operation and maintenance (O\&M), and capital cost. Some auxiliary equations must be developed to achieve equality between the number of variables and equations, which can then be solved numerically. A further explanation of this method was given in [25,31]. The cost balance equation for the $k$ th component takes the form:

$$
\sum_{e} \dot{C}_{e, k}+\dot{C}_{w, k}=\dot{C}_{q, k}+\sum_{i} \dot{C}_{i, k}+\dot{Z}_{k}^{T}
$$

where $\dot{Z}_{k}^{T}$ is equal to the sum of the cost rates of capital plus O\&M. $\dot{C}$ refers to the cost rate. Table 2 shows the exergoeconomic models for the main components of the proposed systems.

Table 2. Exergetic cost balance equations for the main components of the proposed system under steady-state conditions.

\begin{tabular}{|c|c|c|c|c|c|}
\hline No. & \multicolumn{2}{|c|}{ Component } & Schematic & Cost Balance Equation & Auxiliary Equations \\
\hline 1 & \multicolumn{2}{|c|}{ Compressor } & & $\dot{C}_{i}+\dot{C}_{w}+\dot{Z}_{C o m p}=\dot{C}_{e}$ & None \\
\hline 2 & \multirow{2}{*}{ Heat Exchanger } & Condenser & & $\dot{C}_{i h}+\dot{C}_{i c}+\dot{Z}_{c o n d}=\dot{C}_{e h}+\dot{C}_{e c}$ & $\frac{\dot{C}_{i c}}{\dot{E}_{i c}}=\frac{\dot{C}_{e c}}{\dot{E}_{e c}}$ \\
\hline 3 & & Evaporator & & $\dot{C}_{i h}+\dot{C}_{i c}+\dot{Z}_{e v a p}=\dot{C}_{e h}+\dot{C}_{e c}$ & $\frac{\dot{C}_{i h}}{\dot{E}_{i h}}=\frac{\dot{C}_{e h}}{\dot{E}_{e h}}$ \\
\hline 4 & \multicolumn{2}{|c|}{ Membrane } & & $\dot{C}_{i 1}+\dot{C}_{i 2}+\dot{Z}_{m e b}=\dot{C}_{e 1}+\dot{C}_{e 2}$ & $\frac{\dot{C}_{i 2}}{\dot{E}_{i 2}}=\frac{\dot{C}_{e 2}}{\dot{E}_{e 2}}$ \\
\hline 5 & \multicolumn{2}{|c|}{ Mixing Unit } & & $\dot{C}_{i 1}+\dot{C}_{i 2}=\dot{C}_{e}$ & None \\
\hline 6 & \multicolumn{2}{|c|}{ Splitter Unit } & & $\dot{C}_{i}=\dot{C}_{e 1}+\dot{C}_{e 2}$ & $\frac{\dot{C}_{e 1}}{\dot{E}_{e 1}}=\frac{\dot{C}_{e 2}}{\dot{E}_{e 2}}$ \\
\hline 7 & \multicolumn{2}{|c|}{ Throttle } & & $\dot{C}_{i}+\dot{Z}_{T h r}=\dot{C}_{e}$ & $\frac{\dot{C}_{i}}{\dot{E}_{i}}=\frac{\dot{C}_{e}}{\dot{E}_{e}}$ \\
\hline
\end{tabular}

The capital investment cost rate of each component $\left(Z_{k}\right)$ in the proposed system was evaluated based on the cost functions as given in Table $3[32,33]$. The source of the cost in the $k$ th component can be attributed to waste exergy or non-exergy quantities, such as capital cost or O\&M cost. It is helpful for the evaluator during the assessment process to determine the source of the costs in each component to enhance the entire system cost effectiveness. The exergoeconomic factor is considered a good indicator, providing information about the relative weight of each source. 
Table 3. Purchase cost functions for the main equipment components [32,33].

\begin{tabular}{cll}
\hline No. & Component & \multicolumn{1}{c}{ Capital or Investment Cost Function (USD) } \\
\hline 1 & Compressor & $Z_{A C}=\frac{39.5 \dot{m}_{r}}{0.9-\eta_{c}}\left[\frac{P_{e}}{P_{i}}\right] \operatorname{Ln}\left(\frac{P_{e}}{P_{i}}\right)$ \\
\hline 2 & Condenser & $Z_{\text {Cond }}=268.45+\left(516.621 A_{\text {Cond }}\right)$ \\
\hline 3 & Evaporator & $Z_{E v a}=16648.3 A_{\text {eva }} 0.6123$ \\
\hline 4 & Membrane & $Z_{m}=24202 A_{m}^{0.4162}$ \\
\hline 5 & Throttle & $Z_{e x}=114.5 \dot{m}_{r}$ \\
\hline
\end{tabular}

The exergoeconomic factor, $f_{k}$, is defined as the ratio of the non-exergy cost to the overall cost and can be formulated as:

$$
f_{k}=\frac{\dot{Z}_{k}}{\dot{Z}_{k}+c_{f, k}\left[\dot{E}_{d, k+} \dot{E}_{L, k}\right]}
$$

Low values of $f_{k}$ mean the component needs to be improved by reducing its exergy loss and destruction. In contrast, a high value suggests that capital and O\&M costs can be reduced at the expense of component performance.

An exergy assessment of an energy system is highly dependent on the thermophysical properties of the working fluids. The system proposed for this research contains three refrigerants: R410A, R407C, and R134a, selected on the basis of their commercial availability. It is well known that selecting the most appropriate refrigerant will depend on several criteria, the most important of which are the cost, stability, toxicity, flammability, ozone depletion (OD), and effect on global warming (GW) [34]. R410A and R407C are considered good alternative refrigerants to chlorofluorocarbon (CFC) and hydrochlorofluorocarbon (HCFC) refrigerants in A/C systems, with little or no environmental impact on the ozone layer. R410A and R407C are zeotropic refrigerant blends of R32/R125 (50/50 by wt $\%$ ) and R32/R125/R134a (23/25/52 by wt\%), respectively [35]. R134a is a pure hydrofluorocarbon (HFC) refrigerant widely used in A/C systems where, previously, R12/R22 would have been used. Table 4 shows the relevant properties of the selected refrigerants including the Safety Group as per the ASHRAE standard [36].

Table 4. Properties of the refrigerants used in the present study.

\begin{tabular}{cccccccc}
\hline Refrigerant & $\begin{array}{c}\text { Molecular Weight } \\
(\mathbf{k g} / \mathbf{k m o l )}\end{array}$ & $\begin{array}{c}\text { NBP } \\
\left({ }^{\circ} \mathbf{C}\right)\end{array}$ & $\begin{array}{c}\mathbf{T}_{\mathrm{CR}} \\
\left({ }^{\circ} \mathbf{C}\right)\end{array}$ & $\begin{array}{c}\mathbf{P}_{\mathrm{CR}} \\
(\mathbf{M P a})\end{array}$ & ODP & $\begin{array}{c}\text { GWP } \\
(\mathbf{1 0 0})\end{array}$ & $\begin{array}{c}\text { Safety } \\
\mathbf{G r o u p}\end{array}$ \\
\hline R134a & 102.03 & -26.1 & 101.1 & 4.06 & 0 & 1300 & A1 \\
\hline R407C & 86.2 & -43.6 & 86.1 & 4.62 & 0 & 1530 & A1/A1 \\
\hline R410A & 72.56 & -50.5 & 72.5 & 4.96 & 0 & 1730 & A1/A1 \\
\hline
\end{tabular}

\section{Results}

Exergoeconomic and exergy analyses were carried out on an A/C system without and with an air membrane exchanger. The analyses assumed a typical operational environment, ambient pressure $101.3 \mathrm{kPa}$, temperature $35^{\circ} \mathrm{C}$, and $62 \% \mathrm{RH}$. Table 5 presents results for exergetic flow as determined by Al-Sulaiman with R134a as the working medium [18] and as obtained in the current work under the same conditions. 
Table 5. Exergetic data for the proposed air conditioning system.

\begin{tabular}{|c|c|c|c|c|c|c|c|}
\hline State & $\mathrm{P}(\mathrm{kPa})$ & $\mathrm{T}\left({ }^{\circ} \mathrm{C}\right)$ & h (J/kg) & s (J/kg K) & $\omega$ & $\operatorname{Ex}(W)^{a}$ & $\operatorname{Ex}(W)^{b}$ \\
\hline 1 & 300 & 0.65 & 250,831 & 931.0 & - & 1005 & 1005.17 \\
\hline 2 & 1050 & 53.56 & 285,558 & 957.9 & - & 1949 & 1951.64 \\
\hline 3 & 1050 & 41.19 & 110,045 & 400.4 & - & 1310 & 1310.22 \\
\hline 4 & 1050 & 39.94 & 105,474 & 385.8 & - & 1811 & 1816.73 \\
\hline 5 & 300 & 0.65 & 105,474 & 400.2 & - & 1653 & 1657.05 \\
\hline 6 & 1050 & 30.00 & 93,570 & 347.1 & - & 502.7 & 507.76 \\
\hline A & 101.3 & 35.00 & 93.357 & 5.933 & 0.0227 & 0.00 & 0.00 \\
\hline B & 101.3 & 24.60 & 56.948 & 5.811 & 0.0127 & 109.7 & 109.35 \\
\hline $\mathrm{C}$ & 101.3 & 10.65 & 30.801 & 5.720 & 0.008 & 383.6 & 383.17 \\
\hline $\mathrm{D}$ & 101.3 & 20.00 & 40.306 & 5.753 & 0.008 & 253.5 & 252.95 \\
\hline $\mathrm{E}$ & 101.3 & 22.00 & 44.370 & 5.767 & 0.0088 & 212.1 & 211.50 \\
\hline $\mathrm{F}$ & 101.3 & 32.50 & 80.779 & 5.891 & 0.0188 & 11.87 & 11.91 \\
\hline
\end{tabular}

${ }^{\mathrm{a}}$ Al-Sulaiman [18]; ${ }^{\mathrm{b}}$ this work.

Figure 2 presents the rate of exergy destruction as a \% of the total exergy destruction rate for each of: the compressor, Condensers 1 and 2, the evaporator, the membrane, and the throttle when using R410A and R407C as refrigerants. We see that the greatest exergy destruction with refrigerant R410A was for the compressor, $41 \%$, while for refrigerant $407 \mathrm{C}$, it was the $30 \%$ registered with the evaporator. These figures represent the degree of irreversibility in the $\mathrm{A} / \mathrm{C}$ processes involved.

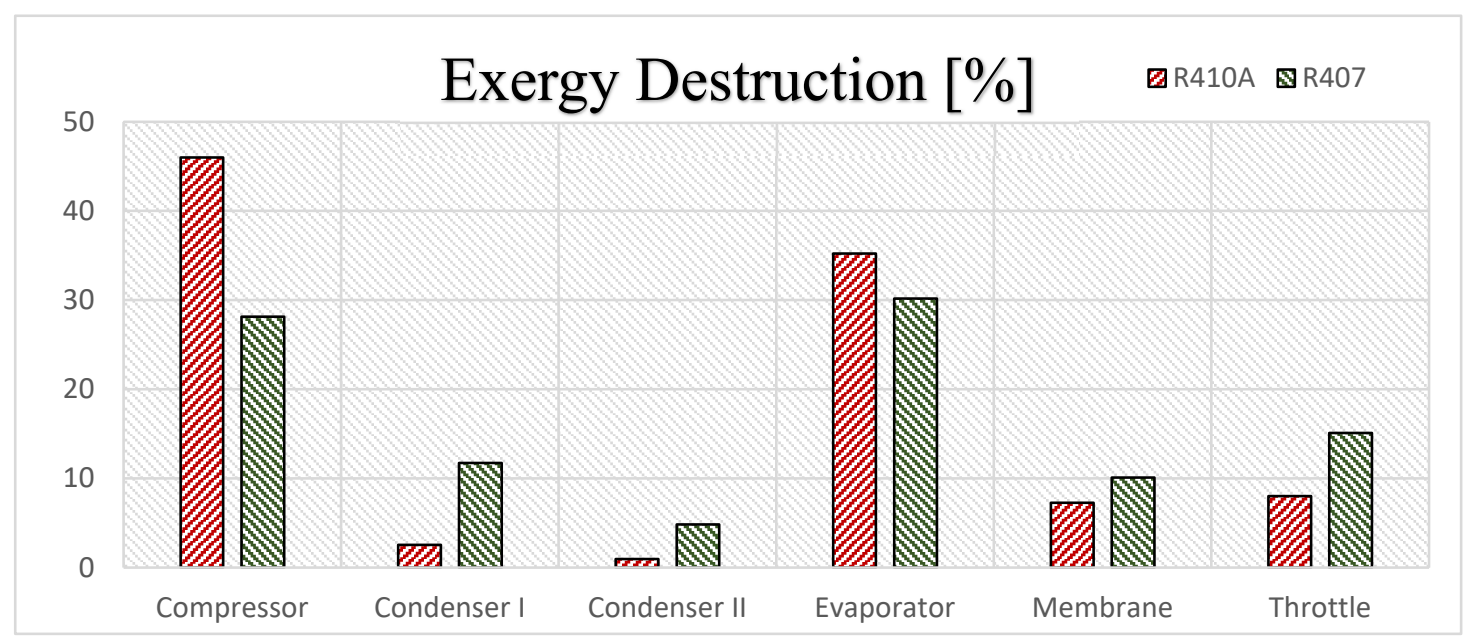

Figure 2. Exergy destruction rate within each component for the proposed air conditioning system as a percentage of the total exergy destruction rate when using refrigerants R410A and R407C.

The high level of exergy destruction (irreversibility) in the compressor when using $\mathrm{R} 410 \mathrm{~A}$ is due to the high level of pressure required with this refrigerant. With the evaporator, the high level of exergy destruction is due to both the evaporation process taking place at low pressure with a high latent heat of evaporation and temperature difference. In total, we see that $81 \%$ and $58 \%$ of the exergy destruction (for R410A and R407C, respectively) occurs in the evaporator and compressor due mainly to thermal and aerodynamic losses. The additional exergy destruction that occurs with R410A is because it has a higher operating pressure than R407C and higher fuel exergy than R407C. Obviously, using a compressor with greater efficiency would consume less power, reducing the fuel exergy, and this 
might be achieved using a lower working pressure as with R407C and R134a. The exergy destruction in the membrane could be due to hydraulic resistance because of fouling.

Figure 3 shows the exergetic efficiency, $\eta e x$, coefficient of performance (COP), and compressor input power as a function the pressure ratio for the proposed A/C system's efficiency using R134a as the refrigerant. As the pressure ratio increased, so did the exergy destruction, which adversely affected the system performance. Thus, both nex and COP decreased as the pressure ratio increased due to an increase in both the losses and fuel exergy. From the figure, we see that $\eta e x$ decreased by about $4 \%$ for every unit increase in the pressure ratio.

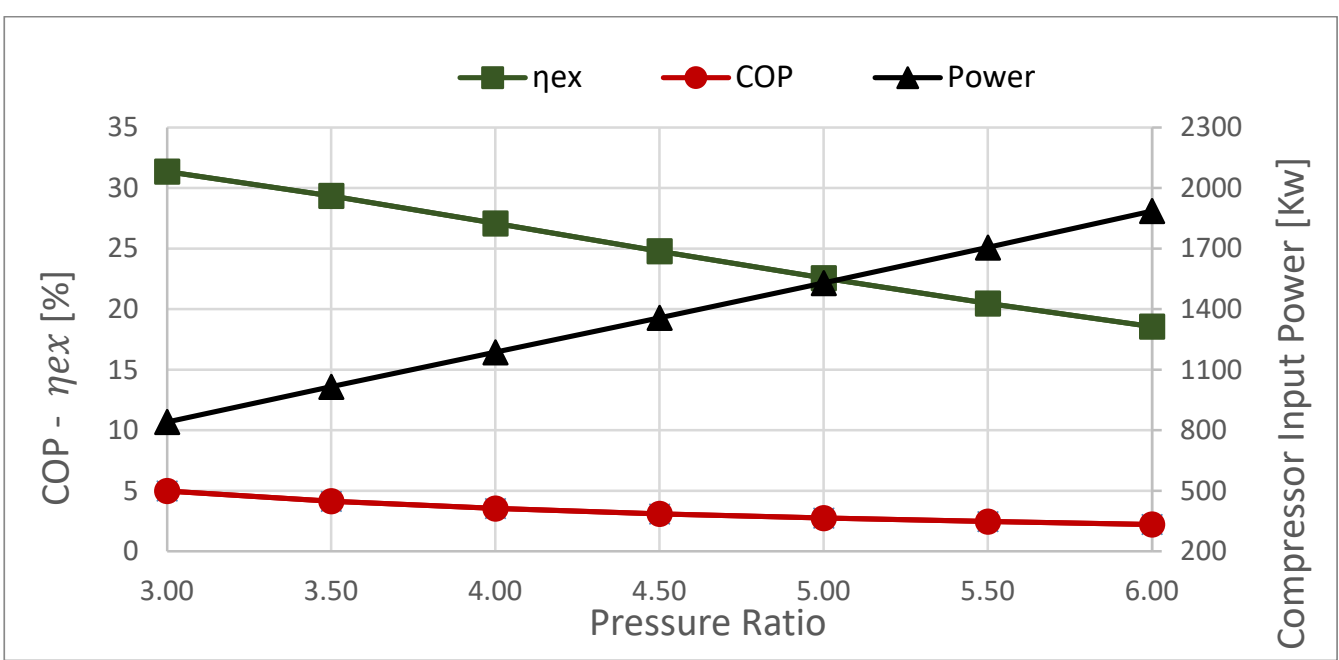

Figure 3. Exergetic efficiency, coefficient of performance, and compressor input power versus pressure ratio for the R134a refrigerant.

Because nex decreased as the pressure ratio increased, the compressor input power increased, proportionately, more than the cooling load on the evaporator, and there would be a corresponding decrease in performance. It follows that using the compressor with a low pressure ratio should enhance efficiency and performance.

As the pressure ratio increased, the contribution that condenser losses make to the total exergy destruction also increased; however, the opposite occurred-though to a lesser degree-in the evaporator, which means system efficiency and performance will vary with compressor operating conditions.

The influence of ambient temperature on the efficiency of the A/C system is shown in Figure 4 when using the R134a refrigerant. Increasing the ambient temperature adversely affected the system efficiency due to an increasing thermal load on the evaporator. The rising ambient temperature increased the exergy destruction through the membrane, and the effect extended to the compressor's power consumption. The membrane works to lower the fresh air temperature before it enters the evaporator, thereby lowering the required $\mathrm{A} / \mathrm{C}$ system power. The compressor's power consumption increased by $15 \mathrm{~kW}$ per ${ }^{\circ} \mathrm{C}$ increase in ambient temperature, due to the change in refrigerant density. The reduction in membrane performance was due to the increased temperature difference between ambient air and inlet temperature to the evaporator. We see that nex decreased as ambient temperature increased; thus, a lower ambient temperature is always preferable. The COP remained almost constant over the range of ambient temperature investigated because the rate at which compressor power input increases is close to the evaporator cooling load. nex is considered a better indicator to evaluate the A/C system's efficiency than the COP, because it takes into account the quality of the energy. 


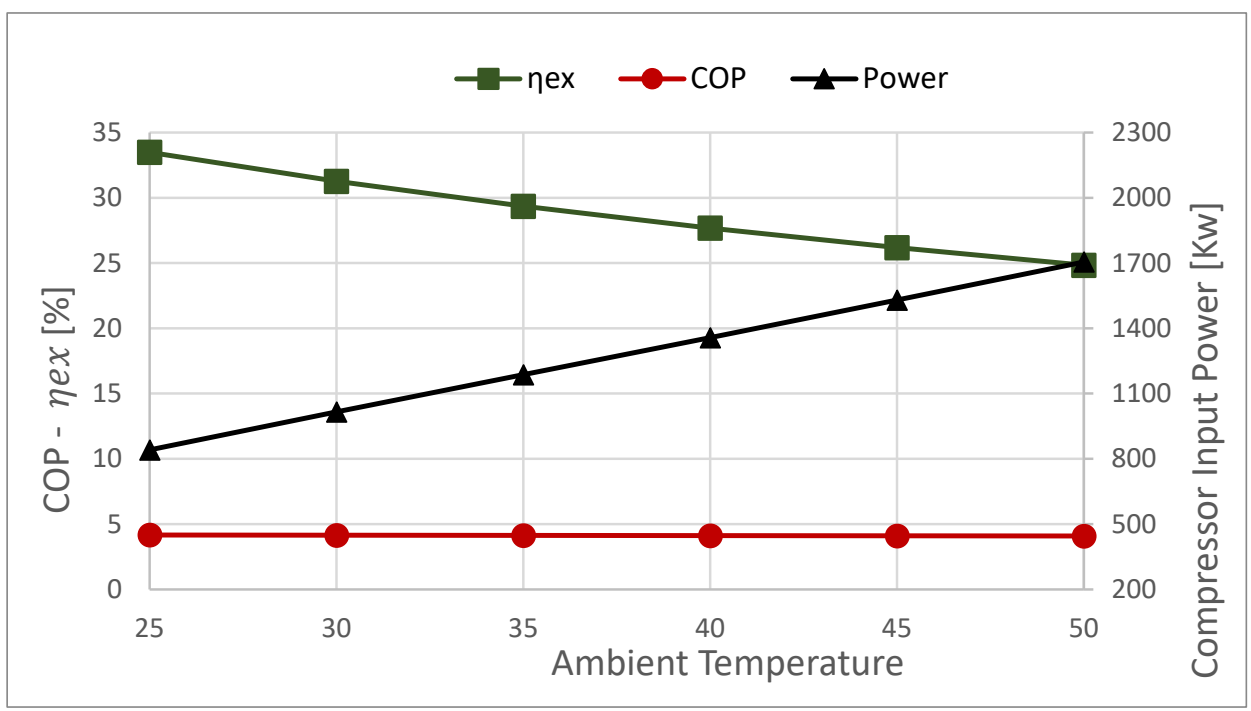

Figure 4. Exergetic efficiency, coefficient of performance, and compressor input power versus ambient temperature for the R134a refrigerant.

The influence of ambient $\mathrm{RH}$ on the $\eta e x$ of the A/C system with R134a as the refrigerant, without $(\eta e x, n)$ and with $(\eta e x, m)$ a membrane, is seen in Figure 5 . We see that as the $\mathrm{RH}$ increased, so did both $\eta e x, m$ and $\eta e x, n$ due to the increase in the cooling load with respect to the fuel exergy. An increase in ambient $\mathrm{RH} \%$ from 30 to 90 increased $\eta e x, m$ from $19 \%$ to $41 \%$ and $\eta e x, n$ from $12 \%$ to $32 \%$. We also see that the system with the membrane present was more efficient due to a reduced rate of exergy destruction. The difference between the two efficiencies was about $10 \%$ and increased very slightly with ambient $\mathrm{RH} \%$. Finally, as is well known, we see that as the ambient $\mathrm{RH} \%$ increased, so did the cooling load and power consumption of the compressor.

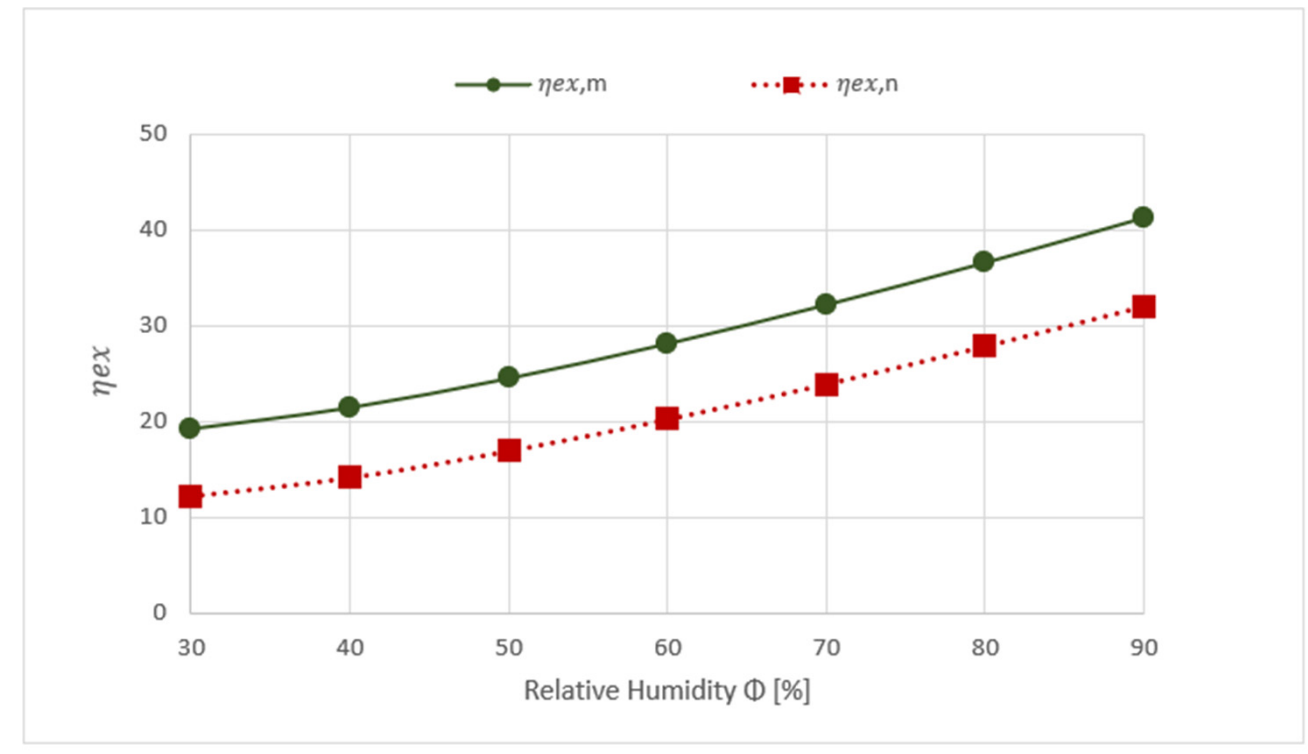

Figure 5. Variation of the exergetic efficiency of the air conditioning system with and without a membrane as a function of the relative humidity for the R134a refrigerant.

Figure 6 shows the $\eta e x$ and COP for the A/C system using three different refrigerants. Refrigerant R134a had the highest values for $\eta e x$ and the COP, followed by R407C, then $\mathrm{R} 410 \mathrm{~A}$. Both $\eta e x$ and the COP showed the same trend for each refrigerant. R407C is considered a good replacement of refrigerant R22 due to the similarity in the operating 
conditions. When R410A is used as a replacement for R22, there is not only reduced efficiency, but more retrofitting is required such as changing the compressor, oil, and filters. Refrigerant R134a used as a replacement needs double the compressor displacement compared to R22 because it has a relatively low pressure.

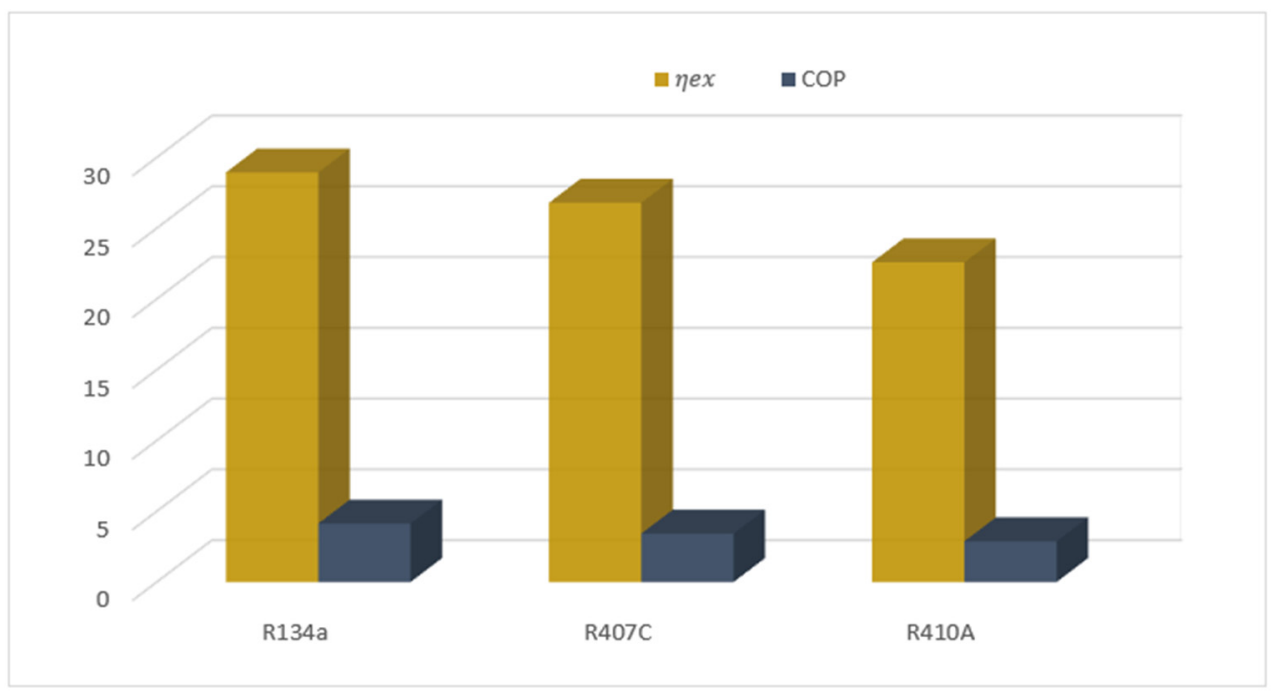

Figure 6. Effect of the refrigerants on the exergy efficiency and coefficient of performance of the air conditioning system.

The variation of $\eta e x$ and $\dot{E}_{d}$ for the A/C system, as a function of ambient temperature with and without a membrane when using R410A as the refrigerant, is presented in Figure 7. The $\eta e x$ for both configurations decreased when the ambient temperature increased. The rate of reduction of nex in the non-membrane system was higher due to the presence of the membrane, which reduced the temperature of the air before it entered the evaporator. The difference in the $\eta e x$ values was higher at high temperatures, which means the impact of using a membrane in hot climatic conditions is greater and more favorable. $\dot{E}_{d}$ was lower in the membrane system due to low fuel exergy in the evaporator. In Kuwait, operating conditions for $\mathrm{A} / \mathrm{C}$ units include ambient temperatures of $50{ }^{\circ} \mathrm{C}$ in the summer and $\dot{E}_{d}$ for the non-membrane case will reach double that for the membrane system. The main sources that contribute to $\dot{E}_{d}$ were the compressor and evaporator.

Figure 8 shows the values of $\dot{E}_{d, k}$ for each of the six components of the A/C system with a membrane, against the seven values of the pressure ratio, with $\mathrm{R} 407 \mathrm{C}$ as the refrigerant. We see that the values of $\dot{E}_{d, \text { compressor }}$ and $\dot{E}_{d, \text { condenser }}$ (combined value of Condensers 1 and 2 ) clearly increased with the pressure ratio, while $\dot{E}_{d, \text { evaporator }}$ decreased. We see $\dot{E}_{d, k}$ that was strongly affected by the pressure ratio, and special attention should be paid to these three components regarding their values at the designated design conditions. The value of $\dot{E}_{d, m e m b r a n e}$ decreased with the increase in the pressure ratio, but its value remained relatively small.

Figure 9 shows the values of $\dot{E}_{d, k}$ for each of the five components of the A/C system without a membrane, against the seven values of the pressure ratio, with $\mathrm{R} 407 \mathrm{C}$ as the refrigerant. Clearly, $\dot{E}_{d, \text { compressor }}$ dominated $\dot{E}_{d}$, after which came $\dot{E}_{d, \text { evaporator }}$. When the membrane was present, $\dot{E}_{d, \text { compressor }}$ increased as the pressure ratio increased, while $\dot{E}_{\text {d,evaporator decreased. }}$

The presence of the membrane reduced the value of $\dot{E}_{d \text {,compressor }}$ at every value of the pressure ratio compared to the situation when the membrane was not present. However, the presence of the membrane increased $\dot{E}_{d, \text { condenser }}$ and $\dot{E}_{d, \text { evaporator }}$. 
The fuel depletion ratio $(\delta)$ and productivity lack $(\xi)$ for the two cases at the specified operating conditions are given in Table 6, with R410A used as the refrigerant. The surrounding temperature was $30{ }^{\circ} \mathrm{C}$ with $60 \% \mathrm{RH}$. The main conclusions from Table 6 are: First, in the presence of a membrane, the highest fuel depletion ratio was for the compressor, followed by the evaporator, then, a long way after, came the expansion valve and membrane. This result shows good agreement with the values presented in Figure 2. Second, in the absence of a membrane, the compressor had a slightly higher fuel depletion ratio value than with a membrane. Third, Condenser 2 showed the lowest value. Fourth, the productivity lack indicator showed the same trend and attributed the main source of irreversibility to the compressor and evaporator.

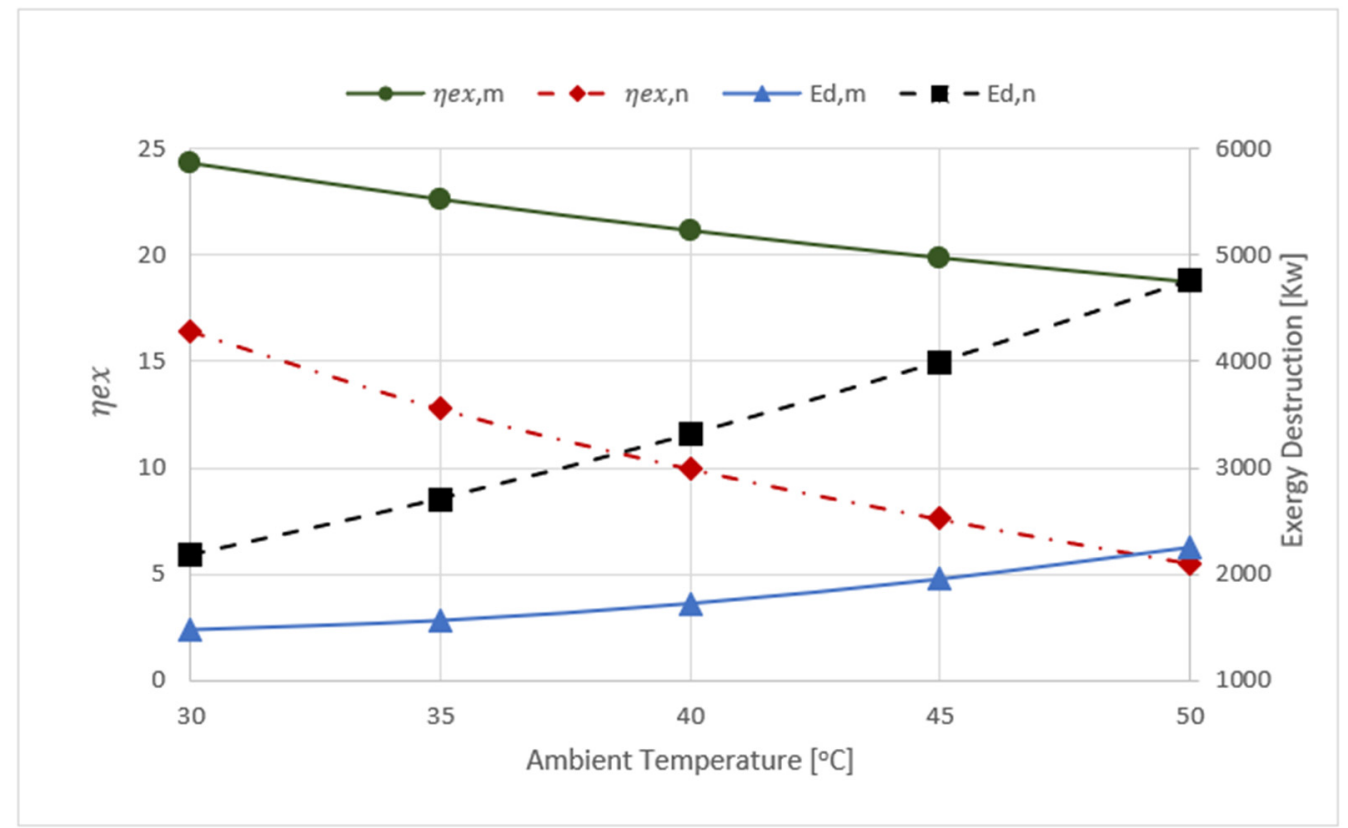

Figure 7. Variations of the exergy efficiency and total exergy destruction without and with a membrane as a function of ambient temperature using the R410A refrigerant.

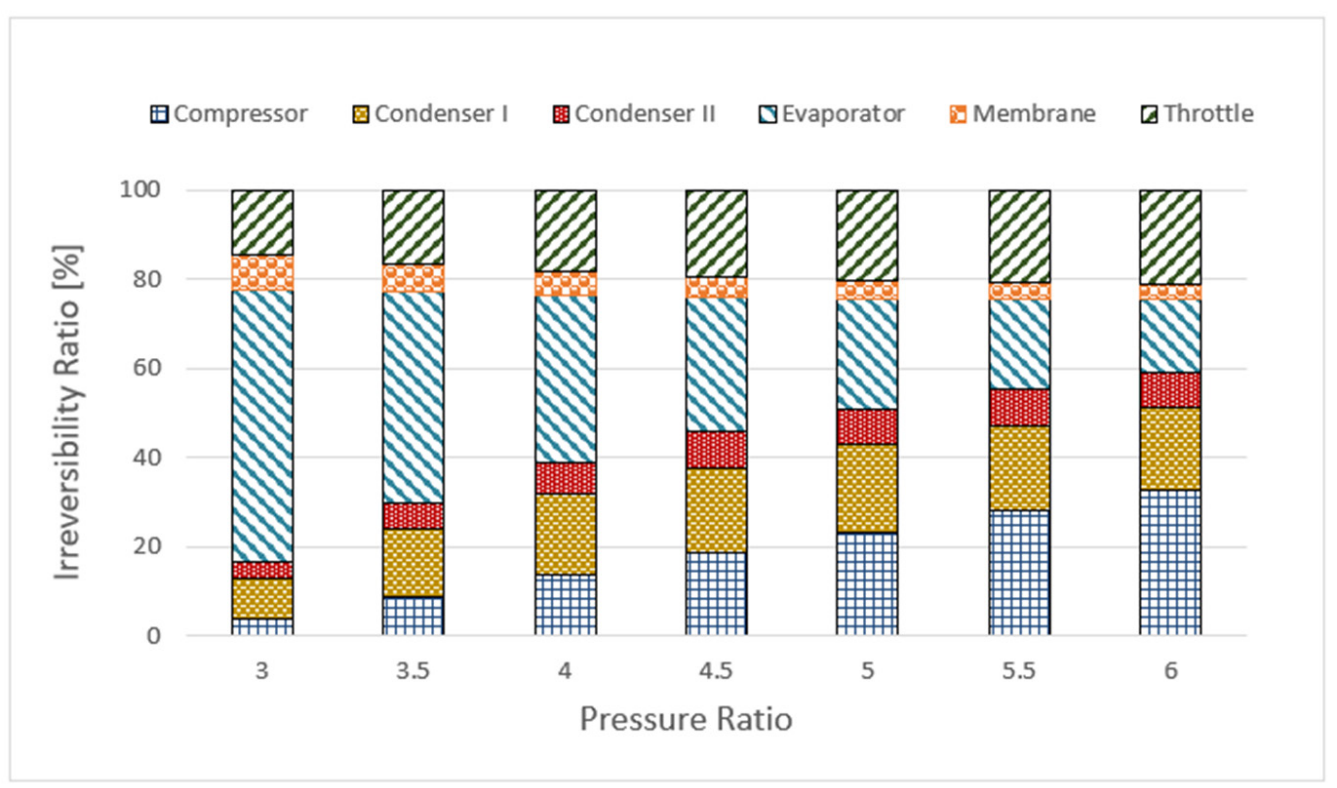

Figure 8. Irreversibility ratios as a function of the pressure ratio for the air conditioning system with a membrane using the $\mathrm{R} 407 \mathrm{C}$ refrigerant. 


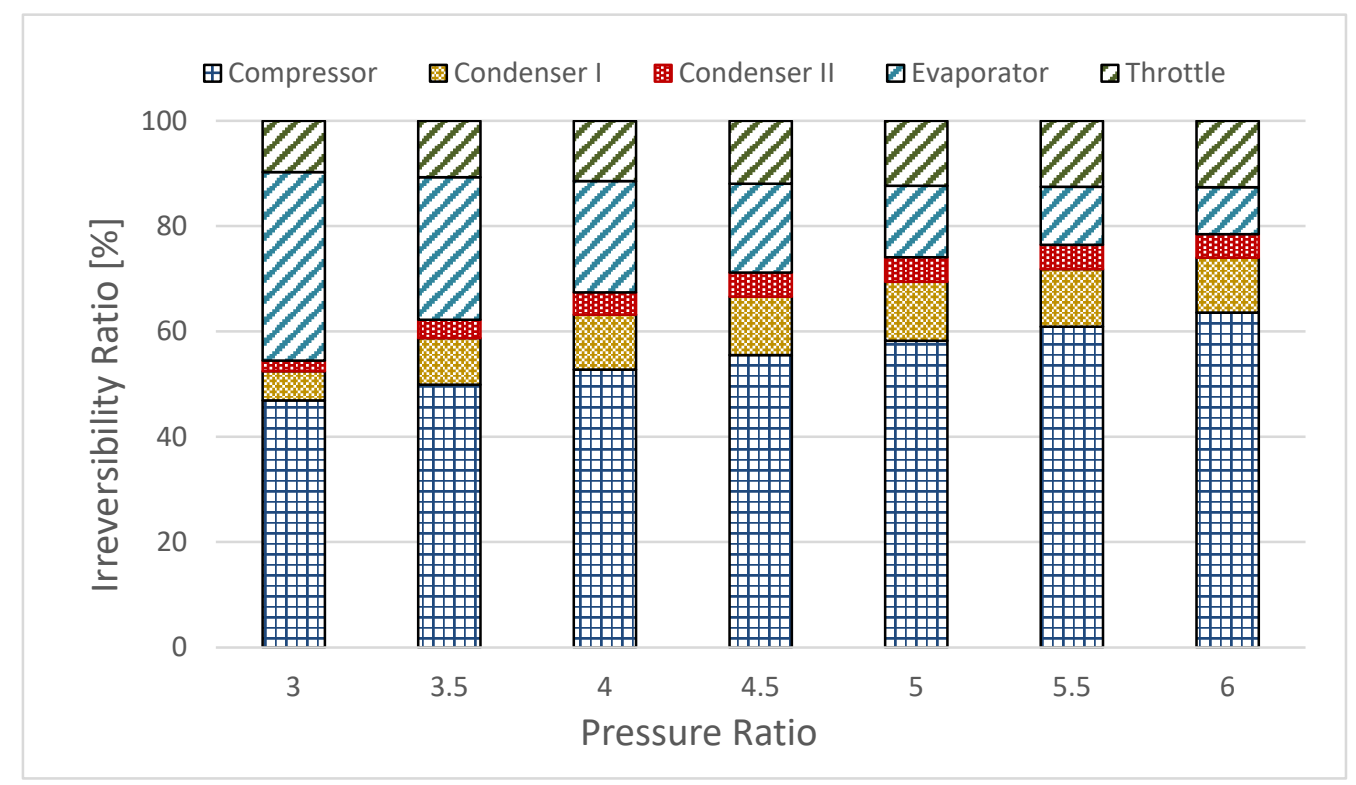

Figure 9. Irreversibility ratios as a function of the pressure ratio for the $\mathrm{A} / \mathrm{C}$ system without a membrane using the R407C refrigerant.

Table 6. Exergy parameters of components without and with a membrane for the R410A refrigerant.

\begin{tabular}{|c|c|c|c|c|c|}
\hline \multirow[b]{2}{*}{ No. } & \multirow[b]{2}{*}{ Component } & \multicolumn{2}{|c|}{ With Membrane } & \multicolumn{2}{|c|}{ Without Membrane } \\
\hline & & $\begin{array}{l}\text { Fuel Depletion Ratio, } \\
\qquad \delta_{x}\end{array}$ & $\begin{array}{c}\text { Productivity Lack } \\
\xi\end{array}$ & $\begin{array}{l}\text { Fuel Depletion Ratio, } \\
\qquad \delta_{x}\end{array}$ & $\begin{array}{c}\text { Productivity Lack } \\
\xi\end{array}$ \\
\hline 1 & Evaporator & 0.380 & 0.117 & 0.496 & 0.153 \\
\hline 2 & Compressor & 0.496 & 0.153 & 0.505 & 0.156 \\
\hline 3 & Condenser 1 & 0.027 & 0.008 & 0.033 & 0.010 \\
\hline 4 & Condenser 2 & 0.010 & 0.003 & 0.004 & 0.001 \\
\hline 5 & Membrane & 0.078 & 0.024 & - & - \\
\hline 6 & Expansion Valve & 0.086 & 0.027 & 0.093 & 0.029 \\
\hline
\end{tabular}

The total cost and exergoeconomic factor for the A/C system with a membrane, using the R410A refrigerant, are presented in Figure 10. The evaporator, compressor, Condenser 1, and membrane were the most important components, from the exergoeconomic viewpoint, to improve the cost effectiveness of the entire system because these components contributed about $86 \%$ of the total cost. The inefficiencies of these components, the exergoeconomic factor being below 50\%, was the cause, so the cost effectiveness of the entire system can be improved by increasing the efficiency of these components at the expense of the non-exergy cost (O\&M and capital costs). The exergoeconomic factor of Condenser 2 was about 63\%; therefore, enhancing the cost effectiveness of the entire system can be achieved by reducing this non-exergy cost.

The present work shed light on a number of important consequences when $\mathrm{A} / \mathrm{C}$ systems are evaluated technically and economically. First, the thermophysical properties of refrigerants have a significant impact on A/C system performance and efficiency. The cooling system is an energy-intensive process, and the challenge is how to determine the efficiency since the quality of the cooling load, as energy, is different from the energy input. Dincer and Rosen [37] studied exergy methods in heating, refrigeration, and A/C systems. They reported various exergy methods and referred to the difficulties in assessing HVAC systems using a single approach, which is unlike the situation with other energy systems such as power plants. That might be attributed to the nature of the cooling process and 
operating conditions, which can be below the reference state of the surroundings. Second, typically with HVAC systems, the operating cost over the book life of the system exceeds the capital cost, and recognizing the status of the system, either new or existing, is critical to determining and evaluating the criteria for economic efficiency.

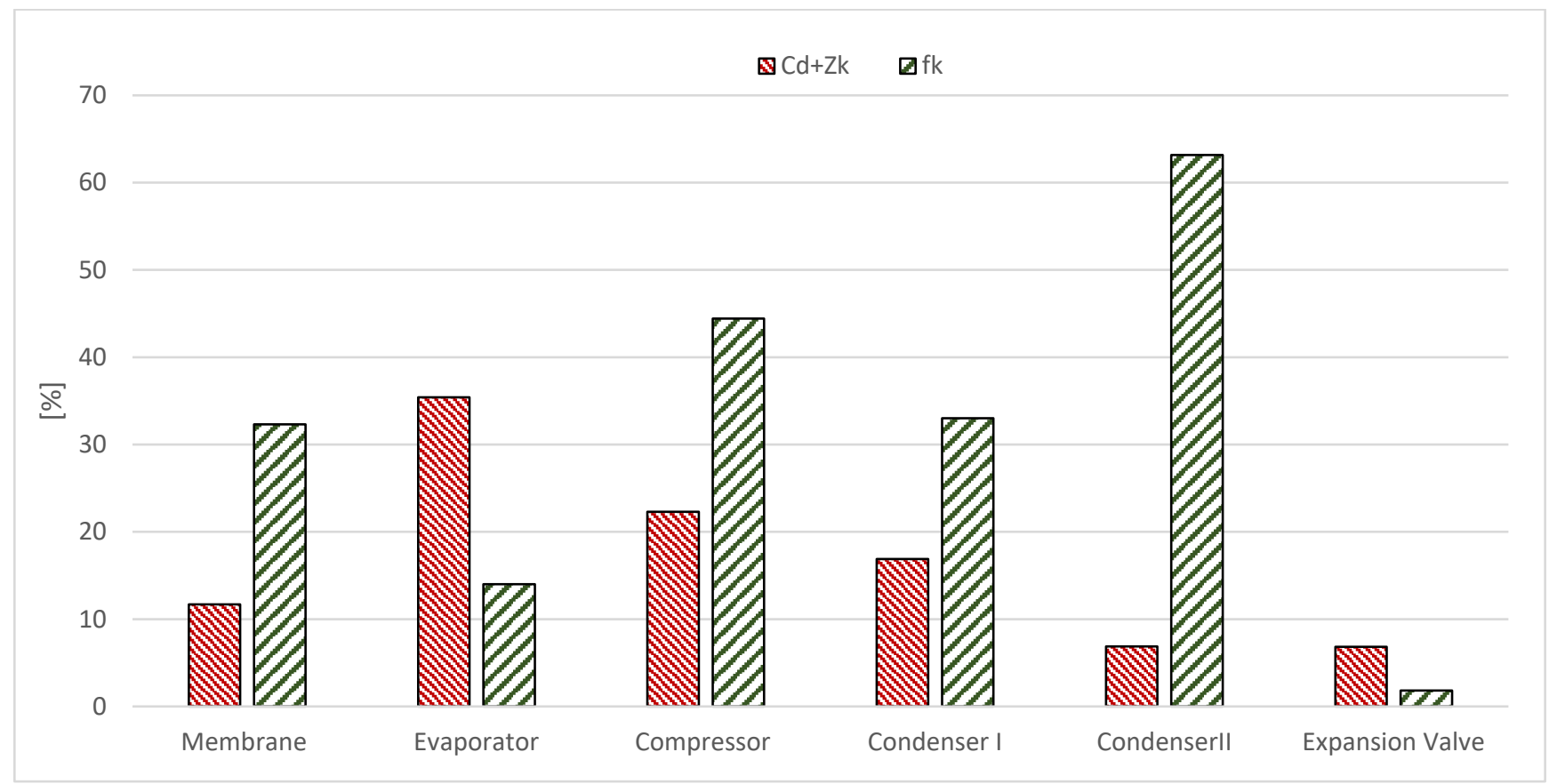

Figure 10. Exergy destruction cost and non-exergy cost $(\mathrm{Cd}+\mathrm{Zk})$ and exergoeconomic factor $\left(f_{k}\right)$ for the air conditioning system with a membrane using the R410A refrigerant.

Most recent commercial refrigerants are environmentally favorable and non-ozone depleting, and the use of techno-economical evaluation is essential in such applications.

\section{Conclusions}

Exergoeconomic and exergy analyses of a generic A/C system with and without an air membrane exchanger using three commercially available refrigerants: R134a, R407C, and R410A, were carried out. The data obtained from a previous study and the results produced by this new model of an A/C system showed good agreement with the results previously published in the literature.

This investigation considered variations in the ambient temperature, $\mathrm{RH}$, and compressor pressure ratio on the efficiency of the proposed system, with the aim of identifying the sources of inefficiencies and their impacts on the cost of the proposed system. This study showed the possibility of improving the performance of A/C systems for a range of working conditions.

The major conclusions from this study were that, under the given test conditions:

- The addition of a membrane to the A/C system significantly improved its efficiency by improving the performance of the evaporator. The benefit obtained by including the membrane in the system increased with the increase in the ambient temperature;

- The pressure ratio had a significant effect on nex and the input power, and it is advised that to obtain better performance, the compressor be used with a low pressure ratio;

- An increase in ambient temperature adversely affected the system efficiency because of the additional thermal load on the evaporator, increased the exergy destruction via the membrane, and increased the power consumption of the compressor;

- When the ambient RH\% increased from 30 to 90, with a membrane, nex increased from $19 \%$ to $41 \%$, and without a membrane, pex increased from $12 \%$ to $32 \%$. 
- The refrigerant with the highest $\eta e x$ and COP was R134a, then R407C, then R410A;

- The evaporator, compressor, Condenser 1, and the membrane contributed about $86 \%$ of the total cost, and from the exergoeconomic viewpoint, improving the cost effectiveness of the entire system will require increasing the efficiency of these components at the expense of the non-exergy cost (capital or O\&M).

- The thermophysical properties of the refrigerants used in A/C systems have a significant effect on their operation. For instance, for R410A, the highest exergy destruction was by the compressor and then the evaporator, but the order was reversed for R407C.

Author Contributions: Conceptualization, A.S.A.; data curation, H.M.A. and A.H.A.; formal analysis, A.S.A. and S.F.A.; investigation, A.S.A., H.H.A. and B.A.; methodology, A.S.A., A.H.A. and H.M.A.; supervision, A.S.A. and S.F.A.; writing-original draft, A.S.A., H.M.A. and H.H.A.; writing-review and editing, A.S.A., A.H.A., H.M.A., S.F.A., H.H.A., and B.A. All authors have read and agreed to the published version of the manuscript.

Funding: This research was funded by the Public Authority for Applied Education and Training (PAAET) grant number TS-18-03.

Acknowledgments: The authors acknowledge the valuable support and assistance provided by the Public Authority for Applied Education and Training (PAAET), in the state of Kuwait, through financial support under Project No. TS-18-03.

Conflicts of Interest: The authors declare no conflict of interest.

\section{Nomenclature}

\begin{tabular}{|c|c|c|c|}
\hline$A$ & Heat transfer surface area & $\mathrm{ch}$ & Chemical \\
\hline $\mathrm{C}$ & Cost factor value & $\mathrm{cv}$ & Control volume \\
\hline$\dot{\mathrm{C}}$ & Cost rate & d & Destruction \\
\hline$\dot{E}$ & Rate of exergy flow in stream & e & Outlet \\
\hline$f$ & Exergoeconomic factor & $\mathrm{f}$ & Fuel \\
\hline$C p$ & Specific heat & $\mathrm{h}$ & Hot stream \\
\hline $\bar{e}_{\mathrm{k}}^{\mathrm{ch}}$ & Specific molar chemical exergy & $\mathrm{i}$ & Inlet \\
\hline$h^{k}$ & Specific enthalpy & $\mathrm{k}$ & Component \\
\hline$\dot{m}$ & Mass flow rate & ke & Kinetic energy \\
\hline$P$ & Pressure of the stream & o & Reference state \\
\hline$\dot{\mathrm{Q}}$ & Heat transfer rate & $\mathrm{p}$ & Product \\
\hline$R$ & Gas constant & ph & Physical \\
\hline $\bar{R}$ & Universal gas constant & pe & Potentials \\
\hline s & Specific entropy & $\mathrm{r}$ & relative \\
\hline$\dot{S}$ & Entropy generation & $\mathrm{s}$ & Sensible \\
\hline $\mathrm{T}$ & Temperature of the stream & $\mathrm{v}$ & Water vapor \\
\hline$y$ & Mole fraction & $x$ & Total \\
\hline $\mathrm{V}$ & Specific volume & Abbreviations & \\
\hline$\dot{w}$ & Power & $\mathrm{A} / \mathrm{C}$ & Air conditioning \\
\hline$\gamma$ & Irreversibility ratio & CFC & Chlorofluorocarbon \\
\hline$\dot{\mathrm{Z}}$ & Purchase cost rate & $\mathrm{COP}$ & Coefficient of performance \\
\hline Greek letters & & Comp & Compressor \\
\hline $\bar{\lambda}$ & Fuel-to-air ratio in molar bases & Evap & Evaporator \\
\hline$\xi$ & Productivity lack & GW & Global warming \\
\hline$\eta_{e x}$ & Exergetic efficiency & HCFC & Hydrochlorofluorocarbon \\
\hline$\varphi$ & Relative humidity & HFC & Hydrofluorocarbon \\
\hline$\omega$ & Specific humidity & HVAC & $\begin{array}{l}\text { Heating, ventilation, and } \\
\text { air conditioning }\end{array}$ \\
\hline$\delta$ & Fuel depletion ratio & OD & ozone depletion \\
\hline$\varepsilon$ & Effectiveness & O\&M & Operation and maintenance \\
\hline Subscripts & & NBP & Normal boiling point \\
\hline $\mathrm{a}$ & Dry air & $\mathrm{RH}$ & Relative humidity \\
\hline c & Cold stream & SPECO & Specific exergy costing meth \\
\hline
\end{tabular}




\section{References}

1. Ito, A. Dehumidification of air by a hygroscopic liquid membrane supported on surface of a hydrophobic microporous membrane. J. Membr. Sci. 2000, 175, 35-42. [CrossRef]

2. Isetti, C.; Nannei, E.; Magrini, A. On the application of a membrane air-liquid contactor for air dehumidification. Energy Build. 1997, 25.3, 185-193. [CrossRef]

3. Liu, X.H.; Zhang, Y.; Qu, K.Y.; Jiang, Y. Experimental study on mass transfer performances of cross flow dehumidifier using liquid desiccant. Energy Convers. Manag. 2006, 47, 2682-2692. [CrossRef]

4. Zurigat, S.A.; Abu-Arabi, Y.H.; Abdul-Wahab, M.K. Air dehumidification by triethylene glycol desiccant in a packed column. Energy Convers. Manag. 2004, 45, 141-155. [CrossRef]

5. Ismail, T.; Khulbe, A.; Matsuura, K. Gas Separation Membranes: Polymeric and Inorganic; Springer International Publishing: New York, NY, USA, 2015.

6. Zhao, B.; Peng, N.; Liang, C.; Yong, W.F.; Chung, T.S. Hollow fiber membrane dehumidification device for air conditioning system. Membranes 2015, 5, 722-738. [CrossRef]

7. Nagengast, B. 100 years of air conditioning. ASHRAE J. 2002, 44, 44-46.

8. Huang, F.G.; Hong, M.S.; Qin, Y. Fluid flow and heat transfer in hexagonal parallel-plate membrane channels (HPMC): Effects of the channel heights and fluid parameters. Appl. Therm. Eng. 2016, 93, 8-14. [CrossRef]

9. Nizovtsev, A.A.; Borodulin, I.M.; Letushko, Y.V.; Zakharov, N.V. Analysis of the efficiency of air-to-air heat exchanger with a periodic change in the flow direction. Appl. Therm. Eng. 2016, 93, 113-121. [CrossRef]

10. El-Dessouky, W.; Ettouney, T.H.; Bouhamra, M.H. A novel air conditioning system: Membrane air drying and evaporative cooling. Chem. Eng. Res. Des. 2000, 78, 999-1009. [CrossRef]

11. Lingo, L.E., Jr.; Roy, U. Exergy management between a building and its environment for residential HVAC. J. Energy Eng. 2013, 140, 04013023. [CrossRef]

12. Zaw, K.; Safizadeh, M.R.; Luther, J.; Choon, N.K. Analysis of a membrane based air-dehumidification unit for air conditioning in tropical climates. Appl. Therm. Eng. 2013, 59, 370-379. [CrossRef]

13. Xing, R.; Rao, Y.; Tegrotenhius, W.E.; Canfield, N.; Zheng, R.F.; Winiarski, D.W.; Liu, W. Advanced thin zeolite/metal flat sheet membrane for energy efficient air dehumidification and conditioning. Chem. Eng. Sci. 2013, 104, 596-609. [CrossRef]

14. Zhang, L.Z.; Niu, J.L. Energy requirements for conditioning fresh air and the long-term savings with a membrane-based energy recovery ventilator in Hong Kong. Energy 2001, 26, 119-135. [CrossRef]

15. Zhang, L.Z.; Zhu, D.S.; Deng, X.H.; Hua, B. Hermodynamic modeling of a novel air dehumidification system. Energy Build. 2005, 37, 279-286. [CrossRef]

16. Zhang, L.Z. Energy performance of independent air dehumidification systems with energy recovery measures. Energy 2006, 31, 1228-1242. [CrossRef] [PubMed]

17. Liang, C.H.; Zhang, L.Z.; Pei, L.X. Independent air dehumidification with membrane-based total heat recovery: Modeling and experimental validation. Int. J. Refrig. 2010, 32, 398-408. [CrossRef]

18. Al-Sulaiman, F.A. Energy and exergy analyses of an air membrane heat and mass exchanger for air conditioning applications. $J$. Energy Eng. 2017, 143, 04017028. [CrossRef]

19. Al-Sulaiman, F.A. Assessment of next generation refrigerants for air conditioning systems integrated with air-membrane heat and mass exchangers. Energy Convers. Manag. 2017, 154, 344-353. [CrossRef]

20. Voloshchuk, V.; Gullo, P.; Nikiforovich, E.; Buyak, N. Simulation and exergy analysis of a refrigeration system using an opensource web-based interactive tool-Comparison of the conventional approach and a novel one for avoidable exergy destruction estimation. Appl. Sci. 2021, 11, 11535. [CrossRef]

21. Gullo, P. Impact and quantification of various individual thermodynamic improvements for transcritical R744 supermarket refrigeration systems based on advanced exergy analysis. Energy Convers. Manag. 2021, 229, 113684. [CrossRef]

22. Đuranović, M.; Rauch, M.; Galović, A.; Živić, M. Exergy analysis of an air conditioning process. Trans. Famena 2021, 45, 1-12. [CrossRef]

23. Yildiz, G.; Ergün, A.; Gürel, A.E.; Ceylan, I.; Ağbulut, Ü.; Eser, S.; Afzal, A.; Saleel, C.A. Exergy, sustainability and performance analysis of ground source direct evaporative cooling system. Case Stud. Therm. Eng. 2022, 31, 101810. [CrossRef]

24. Blanco-Marigorta, A.M.; Tejero-González, A.; Rey-Hernández, J.M.; Gómez, E.V.; Gaggioli, R. Exergy analysis of two indirect evaporative cooling experimental prototypes. Alex. Eng. J. 2022, 61, 4359-4369. [CrossRef]

25. Bejan, A.; Tsatsaronis, G.; Michael, M. Thermal Design and Optimization; John Wiley \& Sons: Hoboken, NJ, USA, 1996.

26. Almutairi, A.; Pilidis, P.; Al-Mutawa, N. Energetic and exergetic analysis of combined cycle power plant: Part-1 operation and performance. Energies 2015, 8, 14118-14135. [CrossRef]

27. Zhang, L. Total Heat Recovery; Nova Kroshka Books: New York, NY, USA, 2008.

28. Wepfer, W.J.; Gaggioli, R.A.; Obert, E.F. Proper evaluation of available energy for HVAC. ASHRAE Trans. 1979, 85, $214-230$.

29. Marletta, L. Air conditioning systems from a 2nd law perspective. Entropy 2013, 15, 859-877. [CrossRef]

30. Almutairi, A.; Pilidis, P.; Al-Mutawa, N. Exergetic, exergoeconomic and exergoenvironmental analysis of intercooled gas turbine engine. AIAA J. 2016, 5060. [CrossRef]

31. Almutairi, A.; Pilidis, P.; Al-Mutawa, N. Exergoeconomic and sustainability analysis of reheat gas turbine engine. Am. J. Energy Res. 2016, 4, 1-10. [CrossRef] 
32. Sanaye, S.; Shirazi, A. Thermo-economic optimization of an ice thermal energy storage system for air-conditioning applications. Energy Build. 2013, 60, 100-109. [CrossRef]

33. Mosaffa, A.H.; Farshi, L.G. Exergoeconomic and environmental analyses of an air conditioning system using thermal energy storage. Appl. Energy 2016, 162, 515-526. [CrossRef]

34. Yunus, Ç.; Michael, A.B. Thermodynamics an Engineering Approach, 8th ed.; McGraw-Hill Education: New York, NY, USA, 2015.

35. Kasera, S.; Bhaduri, S.C. Performance of R407C as an Alternate to R22: A Review. Energy Procedia 2017, 109, 4-10. [CrossRef]

36. Devotta, S.; Waghmare, A.V.; Sawant, N.N.; Domkundwar, B.M. Alternatives to HCFC-22 for air conditioners. Appl. Therm. Eng. 2001, 21, 703-715. [CrossRef]

37. Dincer, I.; Rosen, M.A. Exergy Analysis of Heating, Refrigerating, and Air Conditioning; Elsevier: Amsterdam, The Netherlands, 2015; ISBN 978-0-12-417203-6. 